\title{
REVIEW
}

\section{Year in review 2010: Critical Care - cardiology}

\author{
Daniel De Backer* and Sabino Scolletta
}

\begin{abstract}
We review key research papers in cardiology and intensive care published during 2010 in Critical Care and quote related studies published in other journals if appropriate. Papers were grouped into the following categories: cardiovascular therapies, biomarkers, hemodynamic monitoring, cardiovascular diseases, and microcirculation.
\end{abstract}

\section{Cardiovascular therapies}

Vasopressor agents are the cornerstone of therapy for patients with septic shock. However, the time at which vasopressor agents should be introduced is controversial. Hamzaoui and colleagues evaluated the hemodynamic effects of early administration of norepinephrine in 105 patients with septic shock with life-threatening hypotension [1]. These patients had already received a limited amount of fluids $(1,000 \mathrm{ml}$ saline). Norepinephrine significantly increased the mean arterial pressure. The cardiac index increased from $3.2 \pm 1.0$ to $3.6 \pm 1.1 \mathrm{l} /$ minute $/ \mathrm{m}^{2}$, which can be related to the beta (increase in heart rate or in contractility) or alpha (increase in preload by venous constriction) adrenergic effects of norepinephrine. The heart rate remained unchanged but the stroke volume increased, as a result of an increase in preload (global end-diastolic volume (GEDV) index increased from $694 \pm 148$ to $742 \pm 168 \mathrm{ml} / \mathrm{m}^{2}$ ) and in contractility (cardiac function index increased from $4.7 \pm 1.5$ to $5.0 \pm 1.6 /$ minute). This effect was also observed in patients with poor cardiac contractility.

Another important issue covered is whether betablockers agents have some protective effects during critical diseases [2]. In this post hoc analysis of a large trial in 314 critically ill patients with acute respiratory failure, oral beta-blockers at admission were associated with a lower risk of in-hospital (hazard ratio 0.33 (0.14 to $0.74), P=0.007$ ) and 1-year mortality (hazard ratio 0.29

*Correspondence: ddebacke@ulb.ac.be

Department of Intensive Care, Erasme University Hospital, Université Libre de Bruxelles, Route de Lennik 808, B-1070 Brussels, Belgium
(0.16 to 0.51$), P=0.0003)$. The beneficial effect of oral beta-blockers at admission holds true in patients with acute renal failure related to cardiac or noncardiac causes. In addition, administration of oral beta-blockers before hospital discharge had additional beneficial effects on 1-year mortality. These results should be cautiously scrutinized. Information was only available on use of beta-blockers prior to admission and at hospital discharge, but not during the acute stage of the disease. The statement 'cessation of established therapy appears to be hazardous' is valid only for cessation at hospital discharge, while putting beta-blockers on hold during the decompensated stages was not investigated. Nevertheless, these results emphasize that every effort should be made to reintroduce usual therapy as soon as possible in patients admitted to the ICU and previously treated with beta-blockers.

Recently it has been shown that post-discharge mortality in patients with heart failure increased in the last two decades while 30-day and in-hospital mortality rates decreased over time [3]. Physicians should hence pay attention not only to implementing the best therapies for acute diseases but also to resuming therapies that may improve long-term outcome when these best therapies need to be transiently withheld.

Left heart failure can contribute to weaning failure $[4,5]$. Using echocardiography in 117 patients before and during the weaning trial, Caille and colleagues observed that - compared with successfully weaned patients patients who failed weaning exhibited at baseline a significantly lower left ventricular ejection fraction and higher filling pressures (mitral E/E' 7.0 (5.0 to 9.2) vs. 5.6 (5.2 to 6.3), $P=0.04$ ) [6]. This association is suggestive but does not prove that heart dysfunction contributed to weaning failure, as filling pressures increased in patients with altered cardiac function both in successful and in unsuccessful weaning trials. Interventional trials can only prove a causal link. Therapeutic options include continuous positive airway pressure and inotropic agents [7], but the effects of vasodilatory agents have not been well defined. Routsi and colleagues evaluated the hemodynamic effects of nitroglycerin in 12 chronic obstructive pulmonary disease patients who failed $\geq 3$ consecutive weaning trials [8]. While the mean systemic arterial pressure, the ratepressure product, the mean pulmonary arterial pressure, 
and the pulmonary artery occlusion pressure increased in failing trials, these variables remained stable during nitroglycerin administration. These favorable hemodynamic effects were associated with a successful spontaneous breathing trial and extubation in $92 \%$ and $88 \%$ of patients, respectively. Nitroglycerin can thus facilitate the weaning by restoring weaning-induced cardiovascular compromise.

\section{Biomarkers}

Myocardial dysfunction is frequent in septic shock. The prognostic significance of tissue Doppler imaging and cardiac biomarkers (B-type natriuretic peptide (BNP), $\mathrm{N}$-terminal pro-B-type natriuretic peptide $\mathrm{P}$ (NTproBNP), and troponin $\mathrm{T}$ ) was investigated in 20 patients with septic shock [9]. An index of left ventricular filling pressures was significantly higher in hospital nonsurvivors and was one of the strongest predictors of outcome, with an area under the receiver operating characteristic (ROC) curve of 0.94 , while for troponin $\mathrm{T}$ it was 0.86, for BNP 0.78, and for NTproBNP 0.67. Multiple logistic regression reported that systolic (ejection fraction) and diastolic dysfunctions, in addition to fluid balance and norepinephrine dosages, were independent predictors of BNP concentration. This study confirmed the important role of myocardial dysfunction in septic shock.

Copeptin is a in an indicator of vasopressin release. Potocki and colleagues evaluated the prognostic value of Copeptin, the C-terminal part of the vasopressin prohormone, alone and combined with NTproBNP in 287 patients admitted with acute dyspnea [10]. Copeptin levels were elevated in nonsurvivors $(n=29)$ compared with survivors at 30 days. When adjusted for common cardiovascular risk factors and NTproBNP, Copeptin was the strongest independent predictor for short-term mortality in all patients and especially in patients with acute decompensated heart failure.

In addition to risk stratification at baseline, biomarkers can also be used to evaluate the response to therapy. In a multicenter Italian observational study, in 287 patients with acutely decompensated heart failure, the evaluated changes in BNP at 24 hours and at discharge predicted adverse events [11]. There were 78 events through follow up (180 days), and in 58 of these patients the BNP level at discharge was $>300 \mathrm{pg} / \mathrm{ml}$. BNP reductions $>25.6 \%$ at 24 hours and $>46 \%$ at discharge were associated with less adverse events. These data indicate that the magnitude of the decrease in BNP and the absolute level of BNP at hospital discharge are predictors of adverse events.

Finally, the usefulness of lactate to detect hemodynamic impairment was evaluated in 1,176 patients with acute myocardial infarction [12]. The study population was divided into tertiles with lactate levels $\leq 1.1(n=410), 1.2$ to $1.7(n=398)$ and $\geq 1.8 \mathrm{mmol} / \mathrm{l}(n=368)$. Factors independently associated with higher lactate levels were hypotension, heart rate, thrombolysis in myocardial infarction flow 0 to 1 , diabetes, and nonsmoking. Mortality at 30 days in the three groups was $2.0 \%, 1.5 \%$, and $6.5 \%$, respectively. Lactate measurements at admission in patients with acute myocardial infarction may help to improve risk stratification.

\section{Hemodynamic monitoring \\ Cardiac output measurements}

This year several studies focused on the validation of new hemodynamic devices or on the validation of existing devices in specific conditions. Pulse wave analysis allows determination of cardiac output (CO). As the different techniques use different algorithms, with or without calibration, their ability to measure $\mathrm{CO}$ and to detect changes in CO may vary [13]. In 17 postoperative cardiac surgery patients, the accuracy, bias, and trending ability of $\mathrm{LiDCO}^{\mathrm{mt}}$ (LiDCO Ltd, Cambridge, UK), $\mathrm{PiCCO}^{\mathrm{m}}$ (Pulsion, Munich, Germany) and FloTrac ${ }^{\mathrm{mit}}$ (Edwards Lifesciences, Irvine, CA, USA) were compared with pulmonary artery catheter $\mathrm{CO}$ determinations (bolus thermodilution or continuously determined). The changes in $\mathrm{CO}$ with the four techniques were evaluated during several interventions (volume, vasopressor/ dilator, and inotrope). The mean $\mathrm{CO}$ values were similar. The mean CO bias for each paired method was $-0.18 \mathrm{l} /$ minute (pulmonary artery catheter- $\mathrm{LiDCO}^{\mathrm{mm}}$ ), $0.24 \mathrm{l} /$ minute (pulmonary artery catheter- $\mathrm{PiCCO}^{\mathrm{mm}}$ ), $-0.43 \mathrm{l} /$ minute (pulmonary artery catheter-FloTrac ${ }^{\mathrm{mm}}$ ), $0.06 \mathrm{l} /$ minute $\left(\mathrm{LiDCO}^{\mathrm{m}}-\mathrm{PiCCO}^{\mathrm{mm}}\right),-0.63 \mathrm{l} /$ minute $\left(\mathrm{LiDCO}^{\mathrm{m} \mathrm{m}}-\right.$ FloTrac $\left.{ }^{\mathrm{mm}}\right)$ and $-0.67 \mathrm{l} /$ minute $\left(\mathrm{PiCCO}^{\mathrm{mm}}-\right.$ FloTrac $\left.^{\mathrm{mm}}\right)$, with limits of agreement of 1.56, 2.22, 3.37, 2.03, 2.97, and $3.44 \mathrm{l} /$ minute, respectively. The instantaneous directional changes between any paired $\mathrm{CO}$ measurements displayed good concordance but poor correlation $\left(r^{2}=0.36,0.11\right.$, $0.08,0.20,0.23$, and 0.11 , respectively). These techniques thus display similar mean $\mathrm{CO}$ values, they often trend differently in response to therapy, and they show different interdevice agreement.

In another trial, $\mathrm{CO}$ provided by the FloTrac ${ }^{\mathrm{Tm}}$ and $\mathrm{PiCCO}^{\mathrm{m} x}$ devices was compared with transpulmonary thermodilution before and after volume and norepinephrine administration in 80 septic patients [14]. The changes in $\mathrm{CO}$ induced by fluid expansion, and especially norepinephrine, were more adequately detected by the $\mathrm{PiCCO}^{\mathrm{Tw}}$ than by the FloTrac ${ }^{\mathrm{Tw}}$ device (better ROC curve area). Even though these data seem to indicate that FloTrac ${ }^{\mathrm{mt}}$ is less reliable than $\mathrm{PiCCO}^{\mathrm{m}}$ to detect changes in $\mathrm{CO}$, the methodology used by the authors favored $\mathrm{PiCCO}^{\mathrm{m}}$ as this device was calibrated by transpulmonary thermodilution at baseline so that the only source of error with $\mathrm{PiCCO}^{\mathrm{m}}$ could be post-intervention errors 
while FloTrac ${ }^{\mathrm{m}}$ was submitted to potential errors at baseline as well as after the intervention.

\section{Volumetric indices}

In addition to $\mathrm{CO}$ measurements, calibrated devices may also provide additional measurements such as extravascular lung water (EVLW) and GEDV. In 30 consecutive autopsies, the measurements obtained with transpulmonary thermodilution $\left(\mathrm{PiCCO}^{\mathrm{m}}\right)$ were compared with postmortem lung weight [15]. EVLW determined using transpulmonary single thermodilution within 48 hours of death correlated closely with postmortem lung weight $(r=0.904, P<0.001)$ but underestimated high values:

$$
\operatorname{EVLW}(\mathrm{ml})=0.56 \times \text { lung weight }(\mathrm{g})-58.0 .
$$

In 27 critically ill children, Lemson and colleagues evaluated the relationship between a chest X-ray score of pulmonary edema, markers of oxygenation, and EVLW [16]. The median EVLW index was $16 \mathrm{ml} / \mathrm{kg}$ (range 6 to 31). There was no significant correlation between EVLW and chest X-ray score or markers of oxygenation. These data indicate neither that chest X-ray and the oxygenation index are proportional to the degree of edema or that EVLW cannot be reliably measured in children. Future research should address this issue.

Finally, the site of injection of fluid bolus for transpulmonary thermodilution was also evaluated [17]. Transpulmonary thermodilution requires indicator injection via a central venous catheter usually placed via superior vena cava access. However, femoral access is sometimes used. Transpulmonary thermodilution and its derived variables, GEDV and EVLW, were compared in 24 patients using injections from both sites. The femoral site overestimated the jugular site (bias: cardiac index $0.3 \mathrm{l} / \mathrm{minute} / \mathrm{m}^{2}$, GEDV $241 \mathrm{ml} / \mathrm{m}^{2}$, and EVLW $0.8 \mathrm{ml} / \mathrm{kg}$ ) with wide limits of agreement (cardiac index $0.7 \mathrm{l} /$ minute/ $\mathrm{m}^{2}$, GEDV $250 \mathrm{ml} / \mathrm{m}^{2}$, and EVLW $3.5 \mathrm{ml} / \mathrm{kg}$ ). The bias is due to a longer transit time from the femoral site, while repeatability of measurements mostly accounts for the wide limits of agreement.

A new system has been developed estimating GEDV and EVLW from a different analysis of the transpulmonary thermodilution curve [18]. The new system (VolumeView $^{\mathrm{mm}}$; Edwards Lifesciences) was compared with the $\mathrm{PiCCO}^{\mathrm{m}}$ system (PulsioCath; Pulsion) in 11 anesthetized and mechanically ventilated pigs. Measurements were made during inotropic stimulation, hypovolemia, hypervolemia, and after inducing acute lung injury (oleic acid). GEDV obtained with both techniques correlated closely $\left(r^{2}=0.79\right)$, with a mean bias of $-11 \pm 80 \mathrm{ml}$ (reference-new) and a percentage error of $14 \%$. EVLW also closely correlated $\left(r^{2}=0.97\right)$, with a mean bias of $-5 \pm 72 \mathrm{ml}$ and a percentage error of $15 \%$. In these experimental conditions, the new and current systems to assess GEDV and EVLW agreed.

\section{Mixed venous saturation and central venous saturation}

Controversy remains regarding the relationship between central venous saturation $\left(\mathrm{ScvO}_{2}\right)$ and mixed venous saturation $\left(\mathrm{SvO}_{2}\right)$ in patients with sepsis or septic shock, and little is known on the potential influence of the source (splanchnic or nonsplanchnic) of sepsis on this relationship. In this prospective observational two-center study, $\mathrm{ScvO}_{2}$ and $\mathrm{SvO}_{2}$ were concurrently determined during the first 24 hours after admission in a group of 53 patients with severe sepsis [19]. A total of 265 paired blood samples were obtained. The bias was minimal, as $\mathrm{ScvO}_{2}$ overestimated $\mathrm{SvO}_{2}$ by less than $5 \%$, but limits of agreement were wide (14\%). Similar bias and agreement were observed for changes in $\mathrm{ScvO}_{2}$ and $\mathrm{SvO}_{2}$. The distribution of the $\mathrm{ScvO}_{2}-\mathrm{SvO}_{2}$ difference was similar in survivors and nonsurvivors, and in patients with sepsis of splanchnic and nonsplanchnic origin.

To further explore which factors affect the gradient between $\mathrm{ScvO}_{2}$ and $\mathrm{SvO}_{2}$, Mozina and Podbregar evaluated whether this gradient may be predicted by measurements of thenar muscle tissue oxygenation $\left(\mathrm{StO}_{2}\right)$ measured with near-infrared spectroscopy [20]. During transient arterial occlusion, $\mathrm{StO}_{2}$ decreases more slowly in sepsis/septic shock patients. In 52 patients with severe left heart failure and severe sepsis/septic shock, the $\mathrm{ScvO}_{2}-\mathrm{SvO}_{2}$ difference correlated with plasma lactate (Pearson coefficient $=0.400, P=0.003$ ) and the $\mathrm{StO}_{2}$ deoxygenation rate (Pearson coefficient $=0.651, P=0.001$ ). This relationship was not affected by dobutamine therapy. It is difficult to know whether this association is due to a common mechanism or just reflects severity of disease.

In an interventional trial, Futier and colleagues evaluated whether the central venous-to-arterial carbon dioxide difference $\left(\mathrm{P}(\mathrm{cv}-\mathrm{a}) \mathrm{CO}_{2}\right)$ could be used to identify persistent low flow after optimization of preload during major abdominal surgery [21]. This trial was a secondary analysis of a study involving 70 adult patients randomized to restricted or conventional fluid administration during surgery [22]. In patients with complications (34\% of total), both mean and minimal $\mathrm{ScvO}_{2}$ were lower than in patients without complications. A minimal $\mathrm{ScvO}_{2}<70 \%$ was independently associated with the development of postoperative complications. $\mathrm{P}(\mathrm{cv}-\mathrm{a}) \mathrm{CO}_{2}$ was larger in patients with complications $(7.8 \pm 2$ vs. $5.6 \pm 2 \mathrm{mmHg}$, $P<0.001)$, even when considering only patients with normal $\mathrm{ScvO}_{2}$. $\mathrm{P}(\mathrm{cv}-\mathrm{a}) \mathrm{CO}_{2}>5 \mathrm{mmHg}$ identified patients with normal $\mathrm{ScvO}_{2}$ who develop complications. The next step would be to evaluate whether implementing $\mathrm{P}(\mathrm{cv}-\mathrm{a})$ $\mathrm{CO}_{2}$ in addition to $\mathrm{ScvO}_{2}$ would lead to better outcomes during goal-directed therapy for high-risk surgery. 
In a retrospective analysis of 256 pediatric ( $<6$ years old) patients submitted to cardiac surgery, Ranucci and colleagues evaluated whether the lowest $\mathrm{ScvO}_{2}$ and the peak lactate value during cardiopulmonary bypass, alone or in combination, may be predictive of major morbidity and mortality [23]. Both the nadir $\mathrm{ScvO}_{2}$ and peak lactate during cardiopulmonary bypass were independently associated with major morbidity and mortality. A combined index $\left(\mathrm{ScvO}_{2}<68 \%\right.$ and peak lactate $\left.>3 \mathrm{mmol} / \mathrm{l}\right)$ provided the highest sensitivity and specificity for major morbidity. Altogether these results suggest that either addition of $\mathrm{P}(\mathrm{cv}-\mathrm{a}) \mathrm{CO}_{2}$ or lactate may help to identify patients at risk of complications and poor outcome after high-risk surgery.

\section{Fluid responsiveness}

Benes and colleagues investigated whether stroke volume variation (SVV), an index of fluid responsiveness, could help to optimize fluid therapy in high-risk surgery [24]. Patients $(n=120)$ undergoing elective intraabdominal surgery were randomly assigned to a control group and a SVV group (SVV <10\%). SVV was measured by the Vigileo/FloTrac system (Edwards Lifesciences). The patients in the SVV group received more colloid intraoperatively and experienced a lower number of hypotensive events. Lactate levels at the end of surgery were lower in this SVV group. Fewer SVV patients developed complications (18 (30\%) vs. 35 (58.3\%), $P=0.0033)$ and the overall number of complications was also reduced (34 vs. $77, P=0.0066)$. No difference in mortality and ICU length of stay was found.

SVV and pulse-pressure variation, however, necessitate a relatively large tidal volume [25,26] and an absence of respiratory movements [27]. In addition, large pulsepressure variation can be observed in patients with acute cor pulmonale [28]. Wyler von Ballmoos and colleagues evaluated whether pulse-pressure variation could predict the response to fluid challenge in 22 patients with pulmonary hypertension (cardiac surgery $n=15$, septic shock $n=7$ ) [29]. Pulse-pressure variation failed to predict volume responsiveness ( $\mathrm{ROC}$ curve area $=0.555$, $P=0.485)$. The same group conducted an experimental study in endotoxic pigs with pulmonary hypertension [30]. Pulse-pressure variation failed to predict volume responsiveness (ROC curve area $=0.604, P=0.461$ ), even after hemorrhage (20\% of estimated blood volume). Even though these studies were limited by the multiple fluid challenges performed in a limited number of patients/ animals, these results suggest that pulse-pressure variation should cautiously be interpreted in patients with pulmonary hypertension.

\section{Cardiovascular diseases}

Patients with septic shock may develop atrial fibrillation. In a 13-month observational period, new-onset atrial fibrillation occurred in 23 (46\%) of the 50 patients with septic shock [31]. ICU mortality in septic shock patients with new-onset atrial fibrillation was higher compared with patients with maintained sinus rhythm (44\% vs. $22 \%, P=0.14)$, especially when restoration of sinus rhythm failed $(71.4 \%$ vs. $21.4 \%, P=0.015)$. It remains uncertain whether atrial fibrillation was a marker of severity or contributed to the poor outcome.

Another important issue is the development of ventricular dysfunction after cardiac surgery [32]. In 108 high-risk patients undergoing valve replacement for aortic stenosis, the authors evaluated which factors were associated with left ventricular dysfunction during weaning from cardiopulmonary bypass. Doppler-derived pulmonary flow indices and tissue Doppler imaging could not be obtained in 14 patients, poor systolic left ventricular was documented in 12 patients, and diastolic dysfunction in 89 patients. During weaning from cardiopulmonary bypass, 38 patients $(40 \%)$ required inotropic and/or mechanical circulatory support. By multivariate regression analysis, three independent variables predicted left ventricular systolic dysfunction: age, aortic clamping time, and transmitral flow propagation velocity. The best cut-off value for the propagation velocity to predict left ventricular dysfunction was $40 \mathrm{~cm} / \mathrm{s}$ (sensitivity $72 \%$ and specificity $94 \%$ ). This study underscores the role of diastolic dysfunction in the development of post-bypass cardiovascular failure.

Biguanide intoxication is characterized by profound lactic acidosis. In a retrospective analysis covering a 5 -year period, the outcome of patients with metforminassociated lactic acidosis and with lactic acidosis of other origin were compared [33]. Metformin-associated lactic acidosis was diagnosed in 10 of 197 patients admitted with lactic acidosis. Compared with lactic acidosis of other origin, arterial blood $\mathrm{pH}$ was significantly lower in metformin-associated lactic acidosis (6.78 (6.5 to 6.94) vs. $7.20(6.46$ to 7.35$))$ and lactate was higher (18.7 \pm 5.3 vs. $11.2 \pm 6.1 \mathrm{mmol} / \mathrm{l})$. Overall mortality, however, was comparable (metformin-associated lactic acidosis 50\%, lactic acidosis of other origin 74\%). Compared with similarly severe lactic acidosis of other origin, the prognosis of metformin-associated lactic acidosis is significantly better.

As biguanide intoxication is associated with oxygen handling in the mitochondria, Protti and colleagues evaluated whether oxygen consumption would be altered in these patients [34]. The authors investigated 24 patients with lactic acidosis due to biguanide intoxication. In 11 patients the oxygen consumption could be measured from the pulmonary artery catheter, and in 13 patients only the arterio-venous difference in oxygen content was available. On day 1, oxygen consumption was markedly depressed $\left(67 \pm 28 \mathrm{ml} / \mathrm{minute} / \mathrm{m}^{2}\right)$ despite a normal CO. 
The arterio-venous difference in oxygen content was abnormally low (around 2.0 to $2.5 \mathrm{ml}$ oxygen/100 ml). Resolution of lactic acidosis was paralleled by an increase in oxygen consumption and arterio-venous difference in oxygen content. Plasma lactate and oxygen consumption were inversely correlated. These results suggest that biguanides directly impair oxygen consumption by mitochondrial toxicity.

\section{Microcirculation}

Microcirculatory dysfunction is now recognized as potentially contributing to sepsis-associated organ dysfunction [35-37]. To evaluate what could be the mechanisms implicated in the development of microvascular dysfunction in sepsis, Doerschug and colleagues evaluated the relationship between the reoxygenation rate in thenar muscle oxygen saturation $\left(\mathrm{StO}_{2}\right.$ reoxygenation rate) after transient arterial occlusion and plasma levels of renin activity and angiotensin II concentration in 30 patients with severe sepsis and 10 healthy subjects [38]. Angiotensin II and plasma renin activity were elevated in septic subjects and the degree of elevation correlated negatively with the $\mathrm{StO}_{2}$ reoxygenation rate. These factors also correlated with the extent of organ failure realized during the first day of sepsis. The rennin-angiotensin system may thus be implicated in the development of microvascular dysfunction, but a causative mechanism cannot be ascertained from these data.

White blood cell adhesion and rolling may also be implicated in the development of microcirculatory dysfunction [39]. Ploppa and colleagues evaluated whether interactions of cell activation, shear stress, and platelets at sites of endothelial injury may explain the maldistribution of activated leukocytes during sepsis away from local sites of infection towards disseminated accumulation at remote sites [40]. Human umbilical venous endothelial cells and polymorphonuclear neutrophils were activated with endotoxin. Adhesion of activated polymorphonuclear neutrophils was highly dependent on shear stress, with marked adhesion of polymorphonuclear neutrophils at low shear stress even in the presence of antagonists. Presence of a platelet-covered endothelial injury with high surface density of P-selectin was the strongest activator for adhesion. Platelets increased neutrophil adhesion. L-selectin shedding and integrin dysfunction render leukocyte adhesion increasingly susceptible to shear stress and alternative adhesion receptors. These effects inhibit recruitment in normally perfused sites with intact endothelium and promote maldistribution towards sites with compromised perfusion or endothelial injury.

As classical resuscitation strategies have minimal or variable impact on microcirculatory alterations [41,42], new therapeutic options are needed. Levosimendan may potentially improve the microcirculation. Morelli and colleagues randomized 40 septic shock patients to receive levosimendan $0.2 \mu \mathrm{g} / \mathrm{kg} /$ minute or dobutamine $5 \mu \mathrm{g} / \mathrm{kg} /$ minute for 24 hours [43]. The sublingual microvascular perfusion increased more in the levosimendan group than in the control group (changes in microcirculatory flow index $47 \%$ vs. $10 \%, P<0.001$ ) and the heterogeneity index decreased in the levosimendan group but not in the control group $(-93 \%$ vs. $0 \%, P<0.001)$. These data suggest that levosimendan may better preserve the microcirculation than dobutamine.

Recombinant human activated protein $\mathrm{C}$ may also improve the microcirculation $[44,45]$. In sheep with septic shock and acute lung injury resulting from smoke inhalation injury [46], recombinant human activated protein $\mathrm{C}$ significantly attenuated the changes in microvascular blood flow to the kidney and spleen compared with control animals $(P<0.05$ each), while blood flow to the ileum and pancreas remained similar between groups. The cerebral blood flow stabilized at baseline levels in sheep treated with recombinant human activated protein $C$ while it significantly increased in controls, due to a loss of cerebral autoregulation. In addition, recombinant human activated protein $\mathrm{C}$ reduced indicators of heart tissue injury (malondialdehyde and nitrotyrosine).

Modulation of the inflammatory response may also be a way to limit microvascular dysfunction. Lectin-like oxidized low-density lipoprotein receptor-1 (LOX-1), the major endothelial receptor for oxidized low-density lipoprotein, is also involved in leukocyte recruitment. A study in endotoxic rats evaluated with intravital microscopy the effects of LOX-1 inhibition on leukocyte adherence and capillary perfusion within the intestinal microcirculation [47]. LOX-1 antibody administration significantly decreased expression of LOX-1 as well as plasma levels of monocyte chemoattractant protein-1. LOX-1 inhibition significantly reduced leukocyte adhesion in intestinal submucosal venules. LOX-1 represents a novel target for the modulation of the inflammatory response within the microcirculation in sepsis but its impact on organ function, and especially on infection control, remains to be determined.

Even though controversial, high-volume hemofiltration is sometimes applied in severe hyperdynamic septic shock patients. Ruiz and colleagues evaluated the impact of high-volume hemofiltration on the sublingual microcirculation in septic shock patients [48]. In this uncontrolled study, 12 septic shock patients (norepinephrine requirements $>0.3 \mu \mathrm{g} / \mathrm{kg} /$ minute and cardiac index $>3.0 \mathrm{l} /$ minute $/ \mathrm{m}^{2}$ ) who underwent a 12-hour high-volume hemofiltration were investigated. The microcirculatory flow index increased after 12 hours of high-volume hemofiltration and this increase persisted 6 hours after stopping the hemofiltration. Other microcirculatory 
indices were unaffected. The value of this therapy remains to be determined.

Microcirculatory perfusion is also altered in patients with cardiogenic shock [49], and the evolution of these alterations is associated with outcome [50]. An intraaortic balloon pump is frequently used to mechanically support the heart and may initially be associated with an improvement in microcirculatory perfusion [51]. Fifteen patients deemed ready for discontinuing intra-aortic balloon pump support were investigated during and 10 minutes after temporarily stopping the balloon pump [52]. Ceasing intra-aortic balloon pump support lowered the mean arterial pressure and increased diastolic pressure. The perfused density of small vessels increased from $5.47 \pm 1.76$ to $6.63 \pm 1.90(P=0.0039)$. These data suggest the intra-aortic balloon pump impairs microvascular perfusion in recovered patients, in opposition to its effects at initiation of therapy.

\section{Abbreviations}

BNP, B-type natriuretic peptide; CO, cardiac output; EVLW, extravascular lung water; GEDV, global end-diastolic volume; LOX-1, lectin-like oxidized lowdensity lipoprotein receptor-1; NTproBNP, N-terminal pro-B-type natriuretic peptide; $\mathrm{P}(\mathrm{CV}-\mathrm{a}) \mathrm{CO}_{2^{\prime}}$ central venous-to-arterial carbon dioxide difference; $\mathrm{ROC}$, receiver operating characteristic; $\mathrm{ScvO}_{2}$, central venous saturation; $\mathrm{StO}_{2}$, thenar muscle tissue oxygenation; $\mathrm{SvO}_{2^{\prime}}$ mixed venous saturation; $\mathrm{SVV}$, stroke volume variation.

\section{Competing interests}

DDB received honoraria for lectures and grant for studies from Edwards Lifesciences and Pulsion, and grants for studies from LiDCO and Vytech. SS received grant for studies from Vytech.

Published: 5 December 2011

\section{References}

1. Hamzaoui O, Georger JF, Monnet X, Ksouri H, Maizel J, Richard C, Teboul JL: Early administration of norepinephrine increases cardiac preload and cardiac output in septic patients with life-threatening hypotension. Crit Care 2010, 14:R142.

2. Noveanu M, Breidthardt T, Reichlin T, Gayat E, Potocki M, Pargger H, Heise A, Meissner J, Twerenbold R, Muravitskaya N, Mebazaa A, Mueller C: Effect of oral beta-blocker on short and long-term mortality in patients with acute respiratory failure: results from the BASEL-II-ICU study. Crit Care 2010, 14:R198.

3. Bueno H, Ross JS, Wang Y, Chen J, Vidan MT, Normand SL, Curtis JP, Drye EE, Lichtman JH, Keenan PS, Kosiborod M, Krumholz HM: Trends in length of stay and short-term outcomes among Medicare patients hospitalized for heart failure, 1993-2006. JAMA 2010, 303:2141-2147.

4. Lemaire F, Teboul JL, Cinotti L, Giotto G, Abrouk F, Steg G, Macquin-Mavier I, Zapol WM: Acute left ventricular dysfunction during unsuccessful weaning from mechanical ventilation. Anaesthesiology 1988, 69:171-179.

5. Lamia B, Maizel J, Ochagavia A, Chemla D, Osman D, Richard C, Teboul JL: Echocardiographic diagnosis of pulmonary artery occlusion pressure elevation during weaning from mechanical ventilation. Crit Care Med 2009, 37:1696-1701.

6. Caille V, Amiel JB, Charron C, Belliard G, Vieillard-Baron A, Vignon P: Echocardiography: a help in the weaning process. Crit Care 2010, 14:R120.

7. Ouanes-Besbes L, Ouanes I, Dachraoui F, Dimassi S, Mebazaa A, Abroug F: Weaning difficult-to-wean chronic obstructive pulmonary disease patients: a pilot study comparing initial hemodynamic effects of levosimendan and dobutamine. J Crit Care 2011, 26:15-21.

8. Routsi C, Stanopoulos I, Zakynthinos E, Politis P, Papas V, Zervakis D, Zakynthinos S: Nitroglycerin can facilitate weaning of difficult-to-wean chronic obstructive pulmonary disease patients: a prospective interventional non-randomized study. Crit Care 2010, 14:R204.
9. Sturgess DJ, Marwick TH, Joyce C, Jenkins C, Jones M, Masci P, Stewart D, Venkatesh B: Prediction of hospital outcome in septic shock: a prospective comparison of tissue Doppler and cardiac biomarkers. Crit Care 2010, 14:R44.

10. Potocki M, Breidthardt T, Mueller A, Reichlin T, Socrates T, Arenja N, Reiter M, Morgenthaler NG, Bergmann A, Noveanu M, Buser PT, Mueller C: Copeptin and risk stratification in patients with acute dyspnea. Crit Care 2010, 14:R213.

11. Di Somma S, Magrini L, Pittoni V, Marino R, Mastrantuono A, Ferri E, Ballarino P, Semplicini A, Bertazzoni G, Carpinteri G, Mule P, Pazzaglia M, Shah K, Maisel A Clopton P: In-hospital percentage BNP reduction is highly predictive for adverse events in patients admitted for acute heart failure: the Italian RED Study. Crit Care 2010, 14:R116.

12. Vermeulen RP, Hoekstra M, Nijsten MW, van $d H$, I, van Pelt $L$, Jessurun GA, Jaarsma T, Zijlstra F, van den Heuvel AF: Clinical correlates of arterial lactate levels in patients with ST-segment elevation myocardial infarction at admission: a descriptive study. Crit Care 2010, 14:R164.

13. Hadian M, Kim HK, Severyn DA, Pinsky MR: Cross-comparison of cardiac output trending accuracy of LiDCO, PiCCO, FloTrac and pulmonary artery catheters. Crit Care 2010, 14:R212.

14. Monnet X, Anguel N, Naudin B, Jabot J, Richard C, Teboul JL: Arterial pressure-based cardiac output in septic patients: different accuracy of pulse contour and uncalibrated pressure waveform devices. Crit Care 2010, 14:R109.

15. Tagami T, Kushimoto S, Yamamoto Y, Atsumi T, Tosa R, Matsuda K, Oyama R, Kawaguchi T, Masuno T, Hirama H, Yokota H: Validation of extravascular lung water measurement by single transpulmonary thermodilution: human autopsy study. Crit Care 2010, 14:R162.

16. Lemson J, van Die LE, Hemelaar AE, van der Hoeven JG: Extravascular lung water index measurement in critically ill children does not correlate with a chest X-ray score of pulmonary edema. Crit Care 2010, 14:R105.

17. Saugel B, Umgelter A, Schuster T, Phillip V, Schmid RM, Huber W Transpulmonary thermodilution using femoral indicator injection: a prospective trial in patients with a femoral and a jugular central venous catheter. Crit Care 2010, 14:R95.

18. Bendjelid K, Giraud R, Siegenthaler N, Michard F: Validation of a new transpulmonary thermodilution system to assess global end-diastolic volume and extravascular lung water. Crit Care 2010, 14:R209.

19. van Beest PA, van Ingen J, Boerma EC, Holman ND, Groen H, Koopmans M, Spronk PE, Kuiper MA: No agreement of mixed venous and central venous saturation in sepsis, independent of sepsis origin. Crit Care 2010, 14:R219.

20. Mozina H, Podbregar M: Near-infrared spectroscopy during stagnant ischemia estimates central venous oxygen saturation and mixed venous oxygen saturation discrepancy in patients with severe left heart failure and additional sepsis/septic shock. Crit Care 2010, 14:R42.

21. Futier E, Robin E, Jabaudon M, Guerin R, Petit A, Bazin JE, Constantin JM, Vallet $B$ : Central venous $\mathrm{O}$ saturation and venous-to-arterial $\mathrm{CO}$ difference as complementary tools for goal-directed therapy during high-risk surgery. Crit Care 2010, 14:R193.

22. Futier E, Constantin JM, Petit A, Chanques G, Kwiatkowski F, Flamein R, Slim K, Sapin V, Jaber S, Bazin JE: Conservative vs restrictive individualized goaldirected fluid replacement strategy in major abdominal surgery: a prospective randomized trial. Arch Surg 2010, 145:1193-1200.

23. Ranucci M, Isgro G, Carlucci C, De La TT, Enginoli S, Frigiola A: Central venous oxygen saturation and blood lactate levels during cardiopulmonary bypass are associated with outcome after pediatric cardiac surgery. Crit Care 2010, 14:R149.

24. Benes J, Chytra I, Altmann P, Hluchy M, Kasal E, Svitak R, Pradl R, Stepan M: Intraoperative fluid optimization using stroke volume variation in high risk surgical patients: results of prospective randomized study. Crit Care 2010, 14:R118

25. De Backer D, Heenen S, Piagnerelli M, Koch M, Vincent JL: Pulse pressure variations to predict fluid responsiveness: influence of tidal volume. Intensive Care Med 2005, 31:517-523.

26. lakhal K, Ehrmann S, Benzekri-Lefevre D, Runge I, Legras A, Dequin P-F, Mercier E, Wolf M, Régnier B, Boulain T: Respiratory pulse pressure variation fails to predict fluid responsiveness in acute respiratory distress syndrome. Crit Care 2011, 15:R85

27. Heenen S, De Backer D, Vincent JL: How can the response to volume expansion in patients with spontaneous respiratory movements be predicted? Crit Care 2006, 10:R102 
28. Mahjoub Y, Pila C, Friggeri A, Zogheib E, Lobjoie E, Tinturier F, Galy C, Slama M, Dupont $\mathrm{H}$ : Assessing fluid responsiveness in critically ill patients: falsepositive pulse pressure variation is detected by Doppler echocardiographic evaluation of the right ventricle. Crit Care Med 2009, 37:2570-2575

29. Wyler vB, Takala J, Roeck M, Porta F, Tueller D, Ganter CC, Schroder R, Bracht H, Baenziger B, Jakob SM: Pulse-pressure variation and hemodynamic response in patients with elevated pulmonary artery pressure: a clinical study. Crit Care 2010, 14:R111.

30. Daudel F, Tuller D, Krahenbuhl S, Jakob SM, Takala J: Pulse pressure variation and volume responsiveness during acutely increased pulmonary artery pressure: an experimental study. Crit Care 2010, 14:R122.

31. Meierhenrich R, Steinhilber E, Eggermann C, Weiss M, Voglic S, Bogelein D, Gauss A, Georgieff M, Stahl W: Incidence and prognostic impact of newonset atrial fibrillation in patients with septic shock: a prospective observational study. Crit Care 2010, 14:R108.

32. Licker M, Cikirikcioglu M, Inan C, Cartier V, Kalangos A, Theologou T, Cassina T, Diaper J: Preoperative diastolic function predicts the onset of left ventricular dysfunction following aortic valve replacement in high-risk patients with aortic stenosis. Crit Care 2010, 14:R101.

33. Friesecke S, Abel P, Roser M, Felix SB, Runge S: Outcome of severe lactic acidosis associated with metformin accumulation. Crit Care 2010, 14:R226.

34. Protti A, Russo R, Tagliabue P, Vecchio S, Singer M, Rudiger A, Foti G, Rossi A, Mistraletti G, Gattinoni L: Oxygen consumption is depressed in patients with lactic acidosis due to biguanide intoxication. Crit Care 2010, 14:R22.

35. De Backer D, Creteur J, Preiser JC, Dubois MJ, Vincent JL: Microvascular blood flow is altered in patients with sepsis. Am J Respir Crit Care Med 2002, 166:98-104.

36. Creteur J, Carollo T, Soldati G, Buchele G, De Backer D, Vincent JL: The prognostic value of muscle $\mathrm{StO}_{2}$ in septic patients. Intensive Care Med 2007, 33:1549-1556.

37. De Backer D, Ospina-Tascon G, Salgado D, Favory R, Creteur J, Vincent JL: Monitoring the microcirculation in the critically ill patient: current methods and future approaches. Intensive Care Med 2010, 36:1813-1825.

38. Doerschug KC, Delsing AS, Schmidt GA, Ashare A: Renin-angiotensin system activation correlates with microvascular dysfunction in a prospective cohort study of clinical sepsis. Crit Care 2010, 14:R24.

39. Croner RS, Hoerer E, Kulu Y, Hackert T, Gebhard MM, Herfarth C, Klar E: Hepatic platelet and leukocyte adherence during endotoxemia. Crit Care 2006, 10:R15.

40. Ploppa A, Schmidt V, Hientz A, Reutershan J, Haeberle HA, Nohe B: Mechanisms of leukocyte distribution during sepsis: an experimental study on the interdependence of cell activation, shear stress and endothelial injury. Crit Care 2010, 14:R201.

41. Ospina-Tascon G, Neves AP, Occhipinti G, Donadello K, Buchele G, Simion D, Chierego M, Oliveira Silva T, Fonseca A, Vincent JL, De Backer D: Effects of fluids on microvascular perfusion in patients with severe sepsis. Intensive Care Med 2010, 36:949-955.
42. De Backer D, Creteur J, Dubois MJ, Sakr Y, Koch M, Verdant C, Vincent JL: The effects of dobutamine on microcirculatory alterations in patients with septic shock are independent of its systemic effects. Crit Care Med 2006, 34:403-408

43. Morelli A, Donati A, Ertmer C, Rehberg S, Lange M, Orecchioni A, Cecchini V, Landoni G, Pelaia P, Pietropaoli P, Van Aken H, Teboul JL, Ince C, Westphal M: Levosimendan for resuscitating the microcirculation in patients with septic shock: a randomized controlled study. Crit Care 2010, 14:R232.

44. De Backer D, Verdant C, Chierego M, Koch M, Gullo A, Vincent JL: Effects of Drotecogin alfa activated on microcirculatory alterations in patients with severe sepsis. Crit Care Med 2006, 34:1918-1924.

45. Donati A, Romanelli M, Botticelli L, Valentini A, Gabbanelli V, Nataloni S, Principi T, Pelaia P, Bezemer R, Ince C: Recombinant activated protein C treatment improves tissue perfusion and oxygenation in septic patients measured by near-infrared spectroscopy. Crit Care 2009, 13(Suppl 5):S12.

46. Maybauer MO, Maybauer DM, Fraser JF, Szabo C, Westphal M, Kiss L, Horvath EM, Nakano Y, Herndon DN, Traber LD, Traber DL: Recombinant human activated protein $\mathrm{C}$ attenuates cardiovascular and microcirculatory dysfunction in acute lung injury and septic shock. Crit Care 2010, 14:R217.

47. Landsberger M, Zhou J, Wilk S, Thaumuller C, Pavlovic D, Otto M, Whynot S, Hung O, Murphy MF, Cerny V, Felix SB, Lehmann C: Inhibition of lectin-like oxidized low-density lipoprotein receptor-1 reduces leukocyte adhesion within the intestinal microcirculation in experimental endotoxemia in rats. Crit Care 2010, 14:R223.

48. Ruiz C, Hernandez G, Godoy C, Downey P, Andresen M, Bruhn A: Sublingual microcirculatory changes during high-volume hemofiltration in hyperdynamic septic shock patients. Crit Care 2010, 14:R170.

49. De Backer D, Creteur J, Dubois MJ, Sakr Y, Vincent JL: Microvascular alterations in patients with acute severe heart failure and cardiogenic shock. Am Heart J 2004, 147:91-99.

50. den Uil CA, Lagrand WK, van der EM, Jewbali LS, Cheng JM, Spronk PE, Simoons ML: Impaired microcirculation predicts poor outcome of patients with acute myocardial infarction complicated by cardiogenic shock. Eur Heart J 2010, 31:3032-3039.

51. Jung C, Rodiger C, Fritzenwanger M, Schumm J, Lauten A, Figulla HR, Ferrari M: Acute microflow changes after stop and restart of intra-aortic balloon pump in cardiogenic shock. Clin Res Cardiol 2009, 98:469-475.

52. Munsterman LD, Elbers PW, Ozdemir A, van Dongen EP, van Iterson $M$, Ince $C$ Withdrawing intra-aortic balloon pump support paradoxically improves microvascular flow. Crit Care 2010, 14:R161.

doi:10.1186/cc10542

Cite this article as: De Backer D, Scolletta S: Year in review 2010: Critical Care - cardiology. Critical Care 2011, 15:241 